\title{
Surgical Management of an Iatrogenic Perforation
}

\author{
Sowmya Halasabalu Kalgeri ${ }^{1}$, Ashwini Tumkur Shivkumar², Parinitha Mysore Shankar ${ }^{3}$ \\ 1, 2, 3 Department of Conservative Dentistry and Endodontics, JSS Dental College \& Hospital, \\ JSSAHER, Mysore, Karnataka, India.
}

\section{PRESENTATION OF CASE}

A 23-year-old female patient reported to the department with the chief complaint of pain and swelling in upper back tooth region since a month. Past history revealed root canal treatment in upper right premolar (14) one year back. On clinical examination, 14 was painful on palpation, with signs of tenderness on percussion. (Figure 1). Further examination revealed increased probing depth of $5 \mathrm{~mm}$ in relation to 14 (buccally). An intraoral periapical radiograph revealed unsatisfactory obturation with separated instrument in the buccal root (Figure 2). Hence retreatment of 14 was planned.

Clinical experience plays a pivotal role in rendering quality treatment to patient and their satisfaction. However, iatrogenic injuries during dental procedures may cause root canal perforation. Root perforation is characterized by communication between the root canal and the external tooth surface which occurs because of resorptive process or iatrogenic exposure. ${ }^{1}$ Perforation is a mechanical or pathological communication between the pulp space and the supporting apparatus of the tooth, which leads to a compromise on the health of the periradicular tissue. ${ }^{2,3}$

Diagnosis of root perforation is mostly based on the symptoms and radiographic examinations, indirect assessment of bleeding using a paper point, apex locator and by dental operating microscope, and CBCT (Cone Beam Computed Tomography). ${ }^{4}$

The interval between perforation and repair is one of the critical factors for success. Considering the strategic value of the tooth an interdisciplinary approach is performed. We report a case repair of lateral root perforation in maxillary pre-molar with Biodentine demonstrating the response of periradicular tissues.

Perforations negatively impact the outcome of endodontic treatments. Studies on prognostic factors showed that perforations in the coronal third of the root with periodontal pocket formation have an unfavourable prognosis. Considering the strategic value of the tooth an interdisciplinary approach is performed. This case report explains about the surgical management of root perforation.

\section{CLINICAL DIAGNOSIS}

Root canal treated 14 with iatrogenic perforation.

\section{DIFFERENTIAL DIAGNOSIS}

Failure of the root canal treatment with apical periodontitis.
Corresponding Author: Dr. Sowmya Halasabalu Kalgeri. Department of Conservative Dentistry and Endodontics, JSS Dental College \& Hospital, JSSAHER, Mysore -570015, Karnataka, India.

E-mail: sowmyahk84@gmail.com

DOI: $10.14260 /$ jemds/2020/695

How to Cite This Article:

Kalgeri SH, Shivkumar AT, Shankar PM, et al. Surgical management of an iatrogenic perforation. I Evolution Med Dent Sci 2020;9(42):3172-3174, DOI: $10.14260 /$ jemds/2020/695

Submission 18-07-2020,

Peer Review 12-09-2020,

Acceptance 18-09-2020,

Published 19-10-2020.

Copyright (c) 2020 Sowmya Halasabalu Kalgeri et al. This is an open access article distributed under Creative Commons Attribution License [Attribution 4.0 International (CC BY 4.0)] 


\section{PATHOLOGICAL DISCUSSION}

Root canal treatment was carried out in two sittings. Access cavity temporary restoration was removed, and secondary caries was excavated. Retrieval of gutta percha was done using Endosolv-E solvent (Septodont, Paris, France) and H-files (Dentsply, Maillefer, Tulsa, USA). On tactile exploration and visual examination of the access cavity three openings were perceived.

Two were the canal orifice and other was the perforation site (labially), that finally led to a diagnosis of symptomatic root canal treated 14 with iatrogenic perforation. Since there was increased probing depth and compromised periodontal tissue, surgical correction of perforation site using Biodentine with concomitant gingival contouring and shaping was planned. Root canal procedure was carried out in 14 . There was no pathology noted on the periapical region of buccal root, so the separated instrument was not disturbed. Clinical crown length available for post endodontic restoration was insufficient hence; glass fiber post was placed in the palatal canal and composite post endodontic restoration was done (Figure 3). To reach the perforation space surgical approach was planned. A written informed consent was obtained from the patient. Under LA (2\% Lignocaine with 1: 100,000 epinephrine solution) full thickness mucoperiosteal flap was raised (Figure 4). Perforation site was identified, granulomatous tissue within the defect area and the epithelium from the inner surface of the flap were carefully removed using curette. The site was thoroughly debrided and cleaned. Biodentine (Septodont, St. Maurdes Fossés, France) was mixed according to manufacturer instruction and the perforation site was sealed (Figure 5). Gingiva was contoured, shaped and flap was repositioned and sutured carefully using 3 - 0 silk sutures. Two weeks review showed satisfactory healing. The crown preparation was modified, and impression was taken. PFM crown was cemented (Figure 6).

\section{DISCUSSION OF MANAGEMENT}

Treatment options for tooth perforation at coronal $1 / 3^{\text {rd }}$ were:

1. Root canal retreatment, perforation repair with a crown

2. Extraction and FPD or RPD

3. Extraction and replacement with an implant

We opted the first option since the patient was young and premolar also contributes for the aesthetics of the patient.

Identification and diagnosis of the root perforation is difficult when it is on the buccal or lingual aspect of the root. The radiographic evaluation is limited due to superimposition of the root surface on the lesion. Perforation occurring at the coronal $1 / 3^{\text {rd }}$ close to the alveolar bone and the epithelial attachment which leads to violation of biological width is critical, as it may lead to periodontal problem. This location has been described as the "Critical Crestal Zone" which generally has the poorest prognosis. ${ }^{4}$

An average $2 \%-12 \%$ of endodontically treated cases have reported accidental root perforations. The reasons of root perforations can be pathological, i.e., secondary to resorption or caries, or iatrogenic that occurs during root canal treatment while access cavity preparation and post space preparation.

Our case had an iatrogenic perforation at the coronal one third. Biodentine was choice of material as it contains tricalcium silicate with additives such as powder and a liquid containing calcium chloride to speed up setting. Calcium silicate materials have excellent biocompatibility and are able to induce calcium-phosphate precipitation at the periodontal ligament interface allowing bony healing.5,6 With a reduced setting time compared to MTA (Mineral Trioxide aggregate), Biodentine is perhaps more user-friendly for perforation repair 7,8 because it has good mechanical strength and is biocompatible and bioactive. ${ }^{9}$ Studies have shown that Biodentine has relatively lesser bacterial leakage compared to MTA-Angelus. This could be attributed to the ability of Biodentine to form and precipitate hydroxyapatite. ${ }^{10}$ It is also capable of inter-tubular diffusion and formation of mineral tags of hydration products leading to hybrid zone formation with dentine.11 Moreover, Biodentine shows better interlocking with dentine compared to MTA because of its smaller particle size and uniform components. ${ }^{12}$ It also showed significantly higher push-out bond strength than MTA when used as root perforation repair materials. ${ }^{13}$

Thus, the successful outcome of long-standing perforations seems to be attributed to removal of contaminants as well as cleansing of the pulp chamber and perforation repairing under aseptic conditions as biological width impingement is of concern when considering the perforation restoration at the sub gingival alveolar crest level, The biologic width provides the natural seal that develops around the tooth protecting the alveolar bone from the infection and the disease ${ }^{14}$ and it is essential for preservation of periodontal health.

With the awareness of the anatomy of the tooth, iatrogenic errors can be avoided. With proper diagnosis and operator skills, managing the perforation should be considered, the outcome is more successful with present advanced biomaterials, thus improving the prognosis.
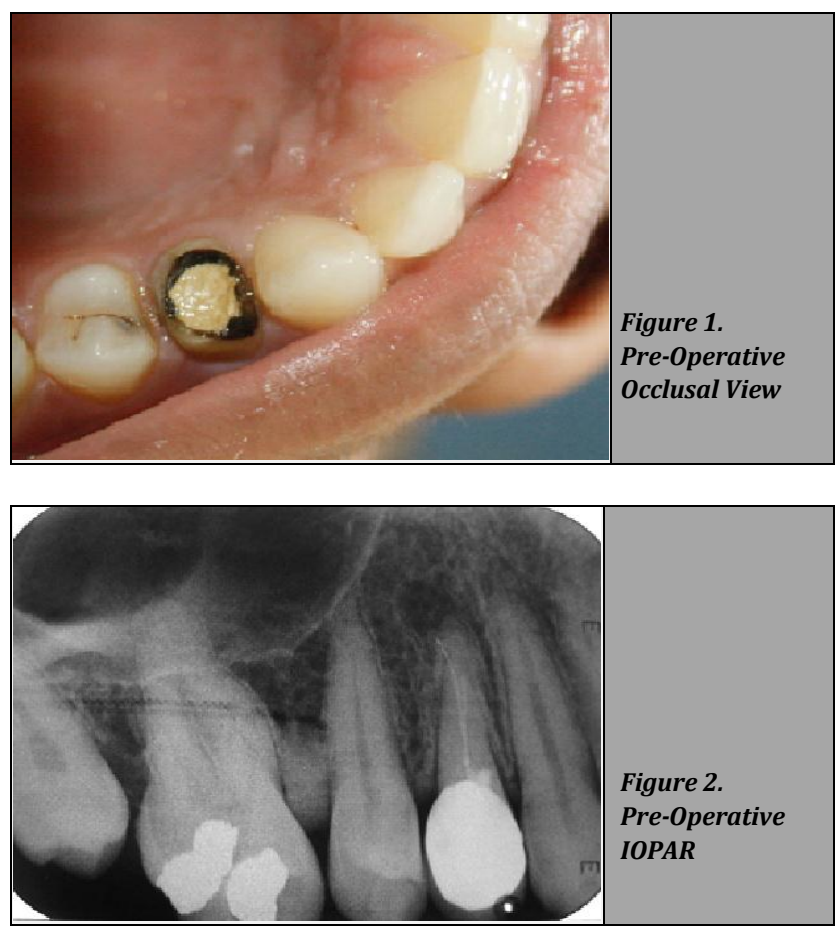

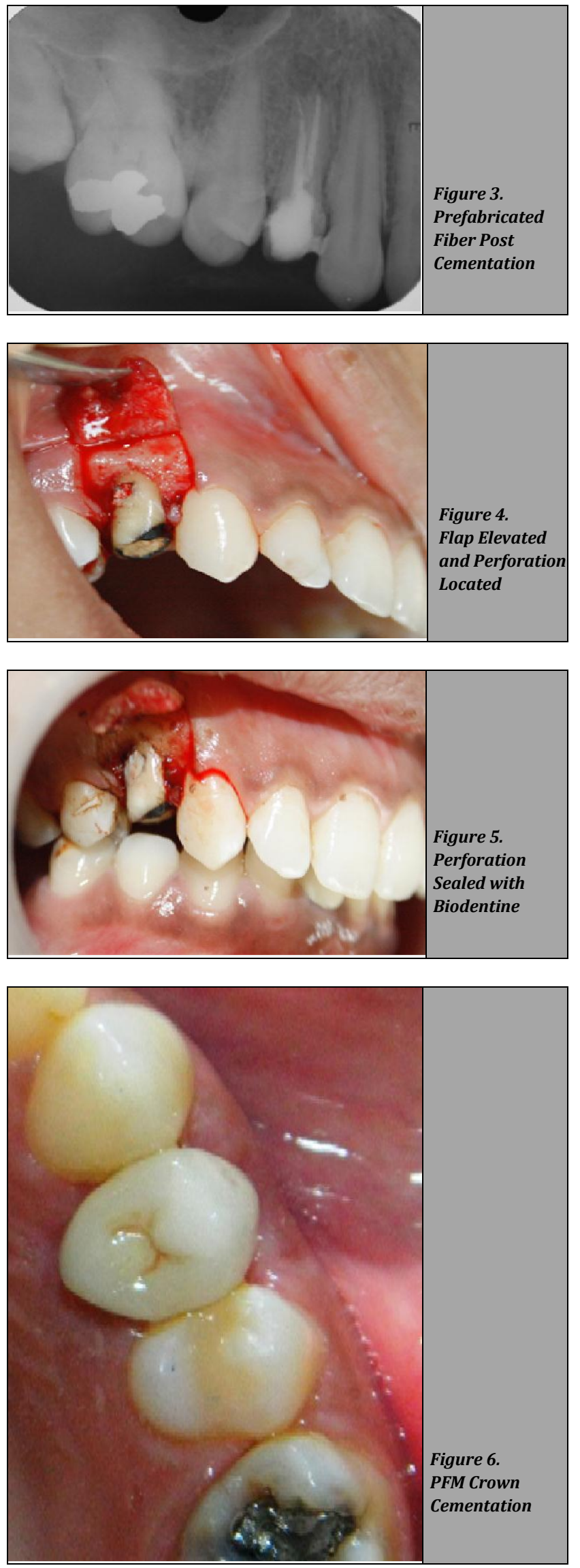

Financial or other competing interests: None.

Disclosure forms provided by the authors are available with the full text of this article at jemds.com.

\section{REFERENCES}

[1] Alkan BA, Yagan AE, Kilic K. Rebuilding anterior dental esthetics: interdisciplinary treatment of an iatrogenically induced marginal tissue recession. Clin Adv Periodontics 2015;5(3):160-4.

[2] Sumanthini MV, Shenoy V, Sharma N. Inter - disciplinary management of an iatrogenic perforation: a case report. Endodontology 2012;2:145-9.

[3] Estrela C, Decurcio DA, Rossi-Fedele G, et al. Root perforations: a review of diagnosis, prognosis and materials. Braz Oral Res 2018;32(Suppl 1):e73.

[4] Balasubramaniam R, Krishnan A, Jayakumar S. Restoring the dignity: case reports of root perforation management. IJADS 2017;3(3):171-4.

[5] Tay FR, Pashley DH, Rueggeberg FA, et al. Calcium phosphate phase transformation produced by the interaction of the Portland cement component of white mineral trioxide aggregate with a phosphate-containing fluid. J Endod 2007;33(11):1347-51.

[6] Torabinejad M, Parirokh M. Mineral trioxide aggregate: a comprehensive literature review--part II: leakage and biocompatibility investigations. J Endod 2010;36(2):190202.

[7] Wongkornchaowalit N, Lertchirakarn V. Setting time and flowability of accelerated Portland cement mixed with polycarboxylate superplasticizer. J Endod 2011;37(3):387-9.

[8] Rhodes J. Nonsurgical retreatment and perforation repair in a maxillary first molar. Endodontic Practice 2015'8(4):36-9.

[9] Malkondu 0, Kazandag MK, Kazazoglu E. A review on biodentine, a contemporary dentine replacement and repair material. Biomed Res Int 2014;2014:160951.

[10] Colon P, Bronnec F, Grosgogeat B, et al. Interaction between a calcium silicate cement (Biodentine) and its environment. J Dent Res 2010;89:401.

[11] Atmeh AR, Chong EZ, Richard G, et al. Dentin-cement interfacial interaction: calcium silicates and polyalkenoates. J Dent Res 2012;91(5):454-9.

[12] Francis T, Joshi SB, Pai ARV, et al. Comparison of the sealing ability of MTA-angelus, biodentine and cem cement in the repair of large furcal perforations-a bacterial leakage study. J Clin Diagn Res 2019;13(1):ZC32-5.

[13] Guneser MB, Akbulut MB, Eldeniz AU. Effect of various endodontic irrigants on the push-out bond strength of biodentine and conventional root perforation repair materials. J Endod 2013;39(3):380-4.

[14] Shivakumar AT, Kalgeri SH, Dhir S. Clinical considerations in restorative dentistry - a narrative review. J Int Clin Dent Res Organ 2015;7(2):122-9. 